\title{
EFFECT OF THERMO-PHOTOCATALYTIC PROCESS USING ZINC OXIDE ON DEGRADATION OF MACRO/MICRO-PLASTIC IN AQUEOUS ENVIRONMENT
}

\author{
NURUL ASHRAF RAZALI*1, WAN RAFIZAH WAN ABDULLAH ${ }^{1,2}$ AND NURAFIQAH \\ MOHD ZIKIR ${ }^{1}$
}

${ }^{1}$ Faculty of Ocean Engineering Technology and Informatics, ${ }^{2}$ Enviromental SustainableMaterial Reasearch Group, Faculty of Ocean Engineering Technology and Informatics, Universiti Malaysia Terengganu, 21030 Kuala Nerus, Terengganu, Malaysia.

*Corresponding author: nrazali@umt.edu.my

Submitted final draft: 19 January $2020 \quad$ Accepted: 20 February $2020 \quad$ http://doi.org/10.46754/jssm.2020.08.001

\begin{abstract}
More than 320 million tons of plastics are produced annually, and the rate of plastic waste generation steadily increases by $3.9 \%$ per year. Introduction of plastic waste into water bodies may lead to many adverse environmental impacts as the plastic debris is very stable and generally requires a longer time to degrade. Over a period of time, bulk plastic debris will slowly degrade into small fragments known as macroplastics (particles size $>5 \mathrm{~mm}$ ) and microplastics (particles size $<5 \mathrm{~mm}$ ). Accumulation of this newly emerging class of pollutants potentially decreases the efficiency of the existing water treatment system. Therefore, improvement on the existing water treatment technique is required. This study aimed at investigating the effect of using the UV-assisted thermo-photocatalytic reaction on the degradation of polypropylene (PP) macro- and microplastics in an aqueous environment for 6 hours. $\mathrm{ZnO}$ nanoparticles $(<50 \mathrm{~nm})$ were employed as the photocatalyst. $2^{3}$ Full Factorial design was carried out in order to identify the correlation between the reaction temperature $\left(35-50{ }^{\circ} \mathrm{C}\right)$, size of PP plastic $\left(25-100 \mathrm{~mm}^{2}\right)$ and the catalyst dosage $(1-3 \mathrm{~g} / \mathrm{L})$ factors and their influences on the weight loss of macro/micro-plastics. Maximum plastic weight loss of $7.8 \mathrm{wt} \%$ was achieved at $50^{\circ} \mathrm{C}, 1 \mathrm{~g} / \mathrm{L} \mathrm{ZnO}$ and $25 \mathrm{~mm}^{2}$ of PP plastic. The interaction between temperature and size must be taken into consideration.
\end{abstract}

Keywords: Microplastic, microplastic, thermo-photocatalytic, zinc oxide, aqueous environment .

\section{Introduction}

More than 320 million tons of plastic products made of polyethylene (PE), polypropylene (PP), polystyrene (PS), polyvinyl chloride $(\mathrm{PVC})$ and many more are produced annually (Benckiser, 2019). Unfortunately, the plastic wastes generated from household materials and industrial sectors steadily increase by $3.9 \%$ per year while almost 12,000 million tons of the wastes have escaped from the waste management cycle and ended in the landfills or discarded into water bodies such as river, lake or ocean (Clean Malaysia, 2016; Valavanidis, 2016). This is undesirable since plastic waste does not decompose or degrade naturally, so they could last for several decades in our valuable water resources if no proper handling is carried out (Bandara et al., 2017).
Introduction of plastic waste into water bodies may lead to many adverse environmental impacts as the plastic debris is very stable and generally requires a longer time to degrade. Over a period of time, bulk plastic debris will slowly degrade into small fragments known as macroplastics (particles size $>5 \mathrm{~mm}$ ) and microplastics (particles size $<5 \mathrm{~mm}$ ) (Piehl et al., 2018). Microplastics can be classified as primary and secondary microplastics. Primary microplastics are small plastic particles which are deliberately produced in this size for use in cosmetic or abrasive products while secondary microplastics are generated during degradation processes (Shim et al., 2017). The fragmentation of plastic macro debris into smaller pieces is promoted by the action of the hydrolysis, photodegradation, mechanical or physical degradation of plastic. 
Several conventional ways to increase degradation of plastics include biodegradation, photodegradation, thermooxidative degradation and thermal degradation approaches (Andrady, 2011). However, these time consuming processes are applied for promoting the fragmentation of plastic waste in a dry condition in the presence of microbial agents, weathering under direct exposure to UV light and chemical decomposition under high temperature (above $100{ }^{\circ} \mathrm{C}$ ). The rate of plastic fragmentation process may vary depending on the plastic's chemical and thermal stability as well as exposure time to degradation agents (Lambert \& Wagner, 2016; Portillo et al., 2016; Weinstein et al., 2016). Noticeable degradation of plastic is commonly observed after weathering test for up to 6 months.

The concern due to the presence of macro or microplastic pollutants in aquatic ecosystems has been highlighted in many recent studies. Accumulation of this newly emerging class of pollutants potentially decreases the efficiency of the existing water treatment system. As a result, many water or wastewater treatment facilities have now become the sink and source of microplastic pollution (Kay et al., 2018; Prata, 2018). Larger plastic debris are generally removed by physical removal process including filtration and sedimentation but the treatment of macro or micro plastic suspended in water is relatively limited. Therefore, improvement on the existing water treatment technique is required to reduce the impacts.

Photocatalytic degradation of polymers stands out as one of the most promising methods because photocatalysis could be viable, inexpensive and energy efficient for polymer degradation (Tofa et al., 2019a). Photocatalysis is a light-mediated redox process. In the presence of appropriate light energy, nanostructured semiconductors excited thus leading to the creation of excited pairs. It will react with surrounding water/moisture to produce superoxides and hydroxyl radicals which are highly reactive species that promote the oxidation of organic species including polymers (Tofa et al., 2019b). Attempts to evaluate the efficiency of photocatalytic treatments of plastic waste in aqueous medium have been previously and most current works extensively focus on the use of $\mathrm{TiO}_{2}$ as photocatalyst material over a range of polymers. Ali et al., (2016) explored the use of $\mathrm{TiO}_{2}$ nanotubes to photocatalytically enhanced degradation of low density PE (LDPE) under UV light. Their findings show that $78 \%$ of $\mathrm{PE}$ degrades in 15 days of reaction. Bandara et al., (2017) reported the degradation of plastic over $\mathrm{TiO}_{2}$ and $\mathrm{ZrO}_{2}$ under sunlight. In this case, the degradation of PE and PP were studied in terms of its morphology and changes in carbonyl index. They reported that both PE and PP undergo progressive oxidation process which promotes fragmentation and decomposition of its structure. Similar observation was emphasised in the work by Zhao et al., (2008). Employment of modified $\mathrm{TiO}_{2}$ enhances the photocatalytic degradation of $\mathrm{PE}$ under sunlight irradiation. During photocatalytic degradation process, direct attack of polymer surface by highly oxidizing radicals in the form of reactive oxygen species (ROS) causes oxidation and breakage of polymer chains. The decomposed chains leached from the bulk as intermediate and simpler compound. A study by Abo et al., (2016) supported that the photocatalysis process can further degrade the by-product from plastic waste decomposition such as Bisphenol A to more than $98 \%$ using $\mathrm{TiO}_{2}, \mathrm{ZnO}$ and $\mathrm{SnO}_{2}$. Although the presence of photocatalyst significantly accelerates the degradation of plastic in water, the treatment time required to achieve satisfactory percentage of plastic removal or degradation is relatively longer compared to the physical removal process like filtration. Some plastic wastes are designed to be highly durable and chemically stable at ambient temperature, thus chemical degradation of plastic through photocatalytic treatment alone is not sufficient to shorten the reaction time. Furthermore, the performance of a photocatalysis system strongly relies on the perfect combination of operating parameters such as temperature, intensity of light, catalyst dosage, dissolved oxygen level and initial concentration of pollutant. Therefore, of the rate decomposition could be maximised 
by conducting the treatment under optimum conditions.

The present work therefore extends previous studies by investigating the effect of thermo-photocatalytic process using $\mathrm{ZnO}$ on degradation of plastic in aqueous environment. In this work, the photocatalytic treatment using reactive $\mathrm{ZnO}$ photocatalyst was performed at elevated temperature (up to $50^{\circ} \mathrm{C}$ ) to promote the photodegradation of plastic debris in water. $\mathrm{ZnO}$ was chosen because of its known photocatalytic effeiciency. Laxma in his review highlighted that the $\mathrm{ZnO}$ has similar band gap energy $(3.37 \mathrm{eV})$ to $\mathrm{TiO}_{2}$ and its electron mobility is much higher than that of $\mathrm{TiO}_{2}$ at a lower cost (Laxma et al., 2018). The thermo-photocatalytic technique is proposed as an alternative method to accelerate the decomposition of macroplastics in the wastewater system. It may assist in reducing the plastic accumulation problem in the water system. The findings from this study may also improve the understanding on the impact of reaction temperature and the amount of catalyst loading on decomposition of macro/ micro-plastics.

\section{Materials and Methods}

\section{Materials}

Commercial $\mathrm{ZnO}$ nanoparticles with a particle size of $\sim 50 \mathrm{~nm}(99.9 \%$, Sigma-Aldrich) were employed as the photocatalyst. Commercially available macro-plastic particles made up of polypropylene (PP) plastic and the plastic sheets were manually cut into small pieces with the dimension $25 \mathrm{~mm}^{2}$ and $100 \mathrm{~mm}^{2}$ and were denoted as the micro-plastic and macro-plastic.

\section{Photocatalytic Testing}

Photodegradation of $25 \mathrm{~mm}^{2}$ and $100 \mathrm{~mm}^{2} \mathrm{PP}$ plastic in $1000 \mathrm{~mL}$ aqueous samples was achieved using batch- slurry photoreactor equipped with an air pump (1.6 L/min) and an ultraviolet lamp with 11 watts of UV-C radiation. The photoreactor was partially immersed in a water bath with temperature controller (GTSONIC Model VGT-1620QTD) to maintain the reaction temperature at a selected setting. The schematic diagram of the experimental set-up is shown in Figure 1. This work evaluates the degradation of PP plastic under the spectrum of $254 \mathrm{~nm}$ at elevated temperature. The macro or microplastic prepared was mixed with 1 or $3 \mathrm{~g} / \mathrm{L}$ of $\mathrm{ZnO}$ in a beaker and was immersed in a water bath for further treatment. Based on our preliminary work, loading the reactor with less than $1 \mathrm{~g} / \mathrm{L}$ of $\mathrm{ZnO}$ in nano-scaled was insufficient to give noticeable effects on the plastic removal process whereas exceeding the load above $3 \mathrm{~g} / \mathrm{L} \mathrm{ZnO}$ produced very turbid solution that hindered penetration of light. Infact, the excess catalyst agglomerated as sediment at the bottom of the reactor. The reaction time was set at 6 hours and the reaction temperature was set up at $35^{\circ} \mathrm{C}$ or $50^{\circ} \mathrm{C}$. The selected reaction time and temperature range simulate the operation of a vast majority solar thermal collector. In the future work, the elevation of operating temperature can be achieved by using a solar thermal collector which converts solar radiation to heat. In addition, increasing the solution temperature above $80^{\circ} \mathrm{C}$ is impracticable due to safety issue and excessive energy usage. The efficiency of the thermo-photocatalytic process in aqueous environment was determined by calculating the difference in weight of PP in percentage plastic before and after the experimental work in percentage as expressed in Equation 1,

$$
\text { Weight loss }(\%)=\frac{W_{i}-W_{f}}{W_{i}} \times 100
$$

where $W_{i}$ is the initial weight of PP plastic before treatment and $W_{f}$ is the final weight of PP after photodegradation treatment. In order to study the impact of multiple treatments, the microplastic $\left(25 \mathrm{~mm}^{2}\right)$ was treated continuously for five repeated cycles in presence of $1 \mathrm{~g} / \mathrm{L}$ $\mathrm{ZnO}$ at $50^{\circ} \mathrm{C}$. The weight loss of PP plastic was measured after each cycle.

\section{Characterisation Techniques}

The surface morphology of PP plastics before and after the treatment was studied by scanning electron microscopy (SEM) (Philip XL40). The 


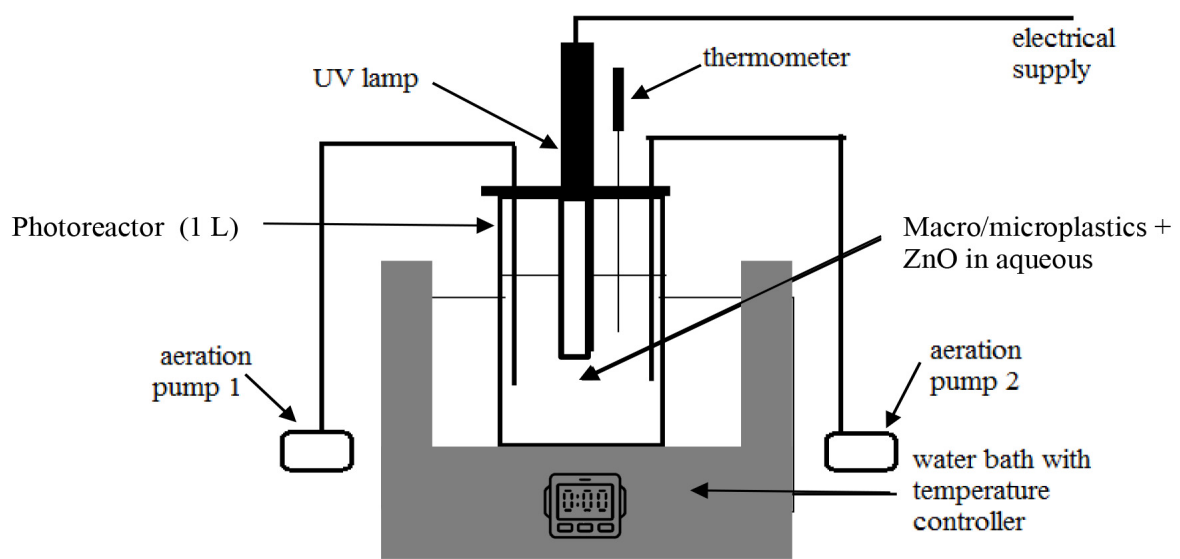

Figure 1: Schematic diagram of the photoreactor set up

PP plastic was mounted on carbon tape and gold coated prior to study. Surface functionalities of the sample were identified by Fourier transform infrared spectroscopy (FTIR) (IR Tracer-100). The data were collected over the range 500 to $4000 \mathrm{~cm}^{-1}$ with a resolution of $4 \mathrm{~cm}^{-1}$. Thermogravimetric analyser (TA Instrument Q50) identified the mass loss of the PP sample over time and relative to temperature change. The temperature was increased from $20^{\circ} \mathrm{C}$ to $500^{\circ} \mathrm{C}$ at a rate of $10^{\circ} \mathrm{C} / \mathrm{min}$ under compressed air purging and macro plastic using thermophotocatalytic technique. In this work, the $2^{3}$ full factorial design was adapted to statistically analysed the individual and interaction effects of the reaction temperature, the plastic's size and the $\mathrm{ZnO}$ catalyst dosage factors on the weight loss of PP during the course of a thermo-photocatalytic treatment. The data was analysed using MiniTab ${ }^{\circledR} 16$ Statistical software. Reaction temperature was set at 35 and $50^{\circ} \mathrm{C}$; while PP macro- and miroplastic were cut into 25 and $100 \mathrm{~mm}^{2} .1$ and $3 \mathrm{~g} / \mathrm{L}$ of $\mathrm{ZnO}$ were employed as the photocatalyst. The highest and lowest value were denoted as +1 and -1 . 24 sets of experiments were conducted with three replicates and the data is summarised in Table 1.

\section{Results and Discussion \\ $2^{3}$ Full Factorial Analysis}

24 sets of experiments were conducted with three replicates using $2^{3}$ Full Factorial design and were analysed using MiniTab® 16 software. The results are summarised in Table 1.

The statistical calculation and regression were performed using MiniTab software. The coefficients for individual and interactive effect of each coefficient and the probability for the full $2^{3}$ factorial designs are tabulated in Table 2. ANOVA analysis is provided in Table 3. All factors are statistically significant as the $\mathrm{P}$ value is smaller than 0.05 . According to the coefficient value, reaction temperature shows a positive impact on the percentage of plastic weight loss. In contrast, the size of PP plastic and the catalyst dosage factors show a negative impact. The first-order model with all possible interactions is shown in Equation 2. This model equation has a very satisfactory fitting as the $\mathrm{R}^{2}=0.9769$ and the $\mathrm{R}^{2}(\operatorname{adj})=0.9721$.

$\%$ Weight Loss $=4.394+1.115 * \mathrm{~T}-1.321 * \mathrm{SIZE}-0.207 * \mathrm{DOSE}-0.565 * \mathrm{~T} * \mathrm{SIZE}$

where $T$ is the temperature factor, SIZE is the plastic size factor and DOSE is the catalyst dosage factor in their corresponding coded forms. 
Table 1: Experimental design matrix and results using $2^{3}$ full factorial technique

\begin{tabular}{|c|c|c|c|c|}
\hline \multirow[t]{2}{*}{ Run } & \multicolumn{3}{|c|}{ Coded Experiments Matrix } & \multirow{2}{*}{$\begin{array}{l}\text { Weight Loss } \\
\text { (\%) }\end{array}$} \\
\hline & Temperature (T) & $\begin{array}{l}\text { Plastic Size } \\
\text { (SIZE) }\end{array}$ & $\begin{array}{l}\text { Catalyst Dosage } \\
\text { (DOSE) }\end{array}$ & \\
\hline 1 & -1 & 1 & -1 & 2.48 \\
\hline 2 & -1 & 1 & 1 & 2.48 \\
\hline 3 & -1 & -1 & 1 & 3.44 \\
\hline 4 & -1 & -1 & -1 & 4.43 \\
\hline 5 & 1 & 1 & 1 & 3.00 \\
\hline 6 & 1 & 1 & -1 & 3.90 \\
\hline 7 & 1 & -1 & 1 & 7.39 \\
\hline 8 & 1 & -1 & -1 & 7.35 \\
\hline 9 & -1 & 1 & 1 & 2.42 \\
\hline 10 & 1 & 1 & -1 & 3.92 \\
\hline 11 & -1 & 1 & -1 & 2.43 \\
\hline 12 & -1 & -1 & -1 & 4.00 \\
\hline 13 & 1 & -1 & 1 & 7.80 \\
\hline 14 & 1 & 1 & 1 & 3.50 \\
\hline 15 & -1 & -1 & 1 & 3.94 \\
\hline 16 & 1 & -1 & -1 & 7.89 \\
\hline 17 & -1 & -1 & 1 & 3.90 \\
\hline 18 & 1 & 1 & -1 & 3.92 \\
\hline 19 & -1 & 1 & -1 & 2.89 \\
\hline 20 & -1 & -1 & -1 & 4.50 \\
\hline 21 & -1 & 1 & 1 & 2.44 \\
\hline 22 & 1 & -1 & -1 & 7.50 \\
\hline 23 & 1 & -1 & 1 & 6.44 \\
\hline 24 & 1 & 1 & 1 & 3.50 \\
\hline
\end{tabular}

Table 2: Estimated effects and coefficients for \% weight loss

\begin{tabular}{cccccc}
\hline Term & Effect & Coef & SE Coef & T & P \\
\hline Constant & - & 4.394 & 0.06455 & 68.08 & $<0.001$ \\
$\mathrm{~T}$ & 2.230 & 1.115 & 0.06455 & 17.27 & $<0.001$ \\
Size & -2.642 & -1.321 & 0.06455 & -20.46 & $<0.001$ \\
Catalyst & -0.413 & -0.207 & 0.06455 & -3.20 & 0.005 \\
$\mathrm{~T}^{*}$ Size & -1.130 & -0.565 & 0.06455 & -8.75 & $<0.001$ \\
\hline
\end{tabular}


Table 3: Analysis of variance (ANOVA) for $\%$ weight loss

\begin{tabular}{lcccccc}
\hline Source & DF & Seq SS & Adj SS & Adj MS & F & P \\
\hline Main effects & 3 & 72.7329 & 72.7329 & 24.2443 & 242.46 & 0.000 \\
$\mathrm{~T}$ & 1 & 29.8374 & 29.8374 & 29.8374 & 298.39 & 0.000 \\
Size & 1 & 41.8704 & 41.8704 & 41.8704 & 418.73 & 0.000 \\
Dose & 1 & 1.0251 & 1.0251 & 1.0251 & 10.25 & 0.005 \\
2-Way Interactions & 1 & 7.6614 & 7.6614 & 7.6614 & 76.62 & 0.000 \\
T*Size & 1 & 7.6614 & 7.6614 & 7.6614 & 76.62 & 0.000 \\
Residual Error & 19 & 1.8999 & 1.8999 & 0.1000 & & \\
Lack of Fit & 3 & 0.1739 & 0.1739 & 0.0580 & 0.54 & 0.663 \\
Pure Error & 16 & 1.7260 & 1.7260 & 0.1079 & & \\
\hline Total & 23 & 82.2942 & & & & \\
\hline
\end{tabular}

Individual plots of the impact of reaction temperature, plastic size and catalysts dosage were generated as shown in Figure 2. High reaction temperature favours the decomposition of PP plastic thus leading to the increment of percentage of weight loss. Heat can influence plastic degradation in several possible ways. Heat can cause thermal oxidative degradation on polymers. However, the polymer must be heated to a sufficiently high temperature that can cause breakage of chemical bonds. Kang et al., (2019) reported that microplastic (about 10\% to $54 \%$ ) decomposed when heated for 8 hours at a temperature between $100{ }^{\circ} \mathrm{C}$ to $160{ }^{\circ} \mathrm{C}$. In the context of this study, exposure of PP to the temperature lower than $50{ }^{\circ} \mathrm{C}$ was not adequate to cause direct thermal decomposition of PP. However, it is proposed that the temperature influences the rate of photo-oxidation reaction on PP. As suggested by Gogotov and Barazov (2012), mild heat treatment $\left(\sim 70{ }^{\circ} \mathrm{C}\right)$ promotes rapid breakdown of polymer chains during photo-oxidation process. Synergistic application of UV-photocatalysis (mediated on $\mathrm{ZnO}$ catalyst) and heat generated different oxidised product on the surface of PP, thus making it more vulnerable to subsequent radical attacks.

PP plastic in smaller size (microplastics) promotes the decomposition process while the amount of catalyst loaded has a little impact. The plastic size factor has interaction effect with the temperature. The influence of plastic size effect on PP decomposition is more prominent at high temperature. The interaction plot in Figure 3 suggests that the combination of high reaction temperature $\left(50{ }^{\circ} \mathrm{C}\right)$ and low size of PP plastic $\left(25 \mathrm{~mm}^{2}\right)$ resulted in high PP weight loss. It was determined that the decomposition of microplastic $\left(25 \mathrm{~mm}^{2}\right)$ was the highest $(7.89 \%)$ upon the introduction of $1 \mathrm{~g} / \mathrm{L}$ of $\mathrm{ZnO}$ and the reaction was carried out at $50^{\circ} \mathrm{C}$. The trend observed in this experiment is comparable to the result reported in Ariza-Tarazaona et al., (2019) that used $\mathrm{N}$ doped $\mathrm{TiO}_{2}$ for degrading high density polyethylene (HDPE). Plastic loss during photodegradation process signified that the PP surface underwent gradual decomposition process. The highly oxidizing radicals namely the $\bullet \mathrm{OH}$ and $\bullet \mathrm{O}_{2}^{-}$radicals photogenerated on the $\mathrm{ZnO}$ surface could aggressively attack the polymeric chains on PP and cause it to oxidised. In comparison to the findings in Ariza-Tarazaona et al., (2019), the treatment time required for decomposing $7 \mathrm{wt} \%$ HDPE is relatively longer (20 hours) as the reaction takes place under 25 ${ }^{\circ} \mathrm{C}$ in the presence of $\mathrm{TiO}_{2}$. $\mathrm{PP}$ treated in this study on the other hand lost similar weight in only 6 hours. 


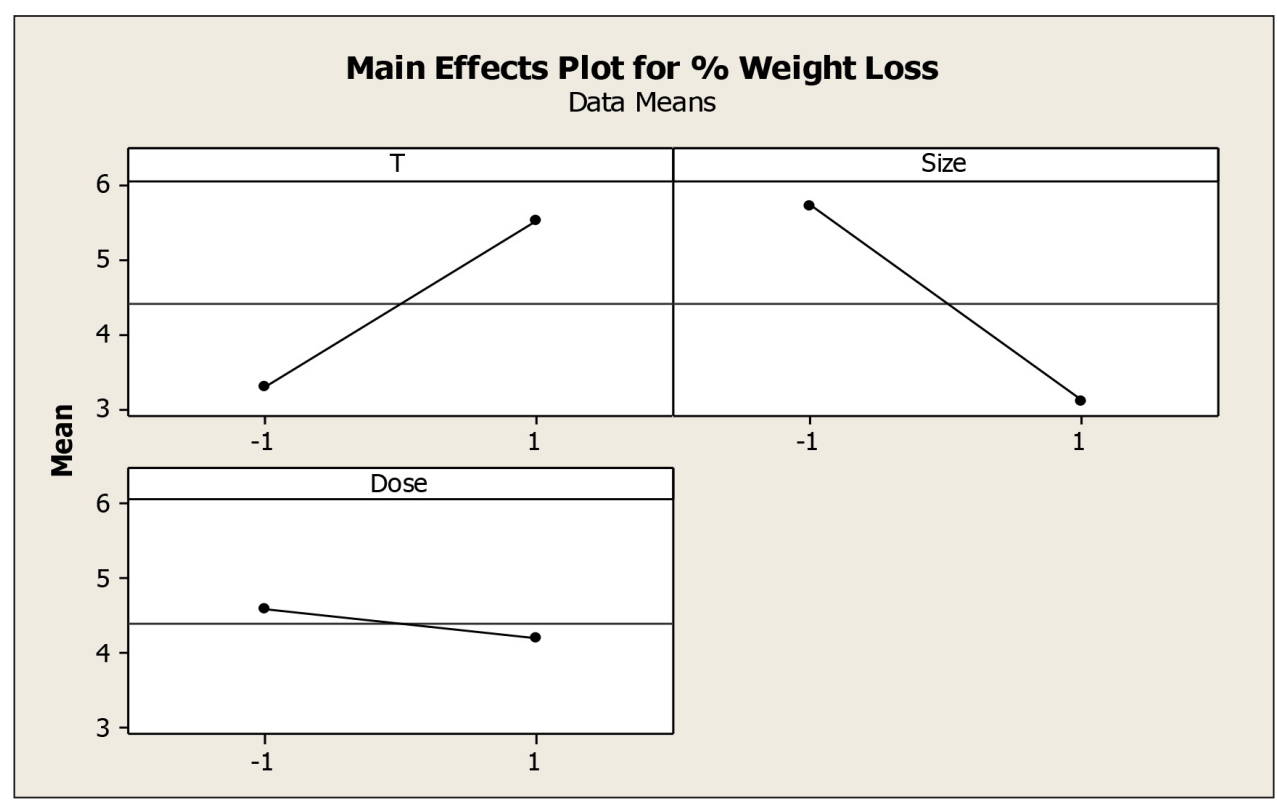

Figure 2: Plot for $\%$ weight loss

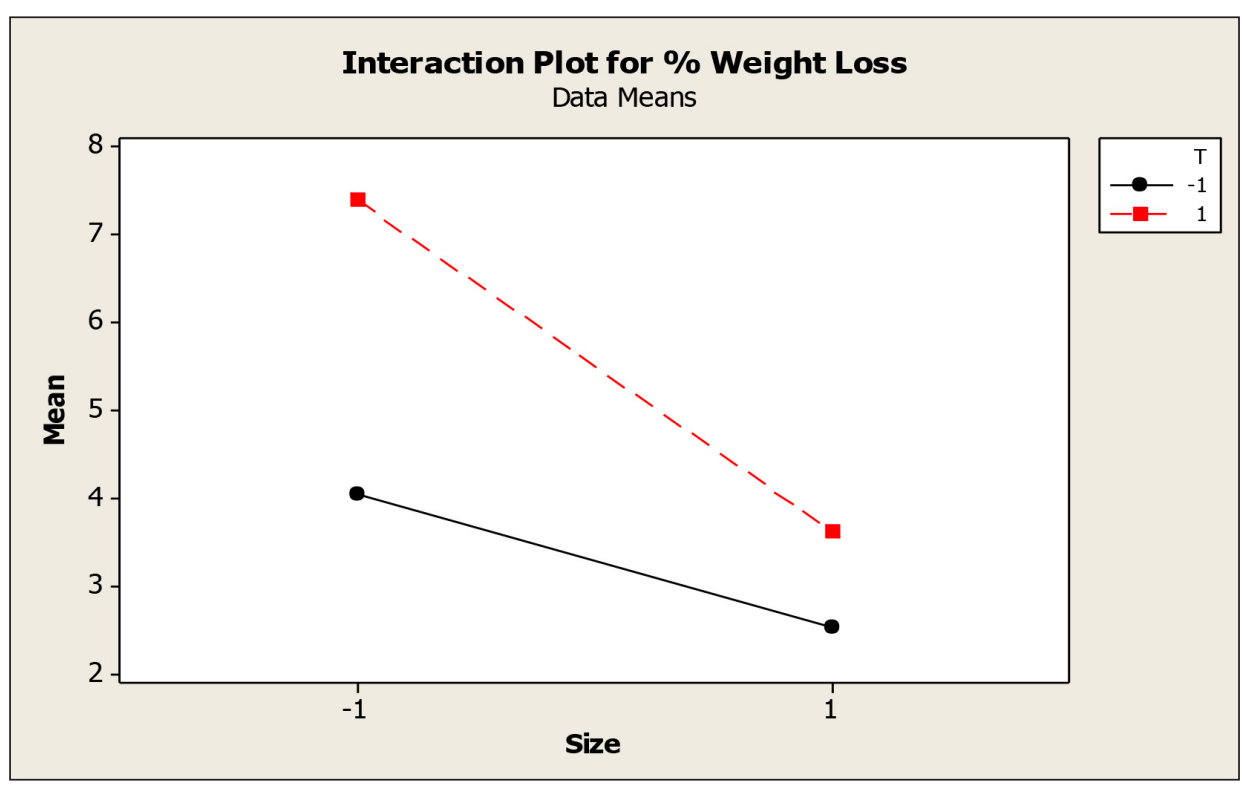

Figure 3: The interaction plot between PP size and reaction temperature and its impact on percentage of weight loss

The contour plots and surface response are shown in Figure 4 and the interaction between all factors were analysed. Based on the finding, it can be predicted that the synergy between the factor of PP plastic size and the reaction temperature factor are very significant. High
PP plastic weight loss $(>7 \%)$ is achieved by carrying thermo-photocatalytic treatment on small PP plastic pieces $\left(25 \mathrm{~mm}^{2}\right)$ at high temperature $\left(50{ }^{\circ} \mathrm{C}\right)$ or low $\mathrm{ZnO}$ catalyst dosage $(1 \mathrm{~g} / \mathrm{L})$. 


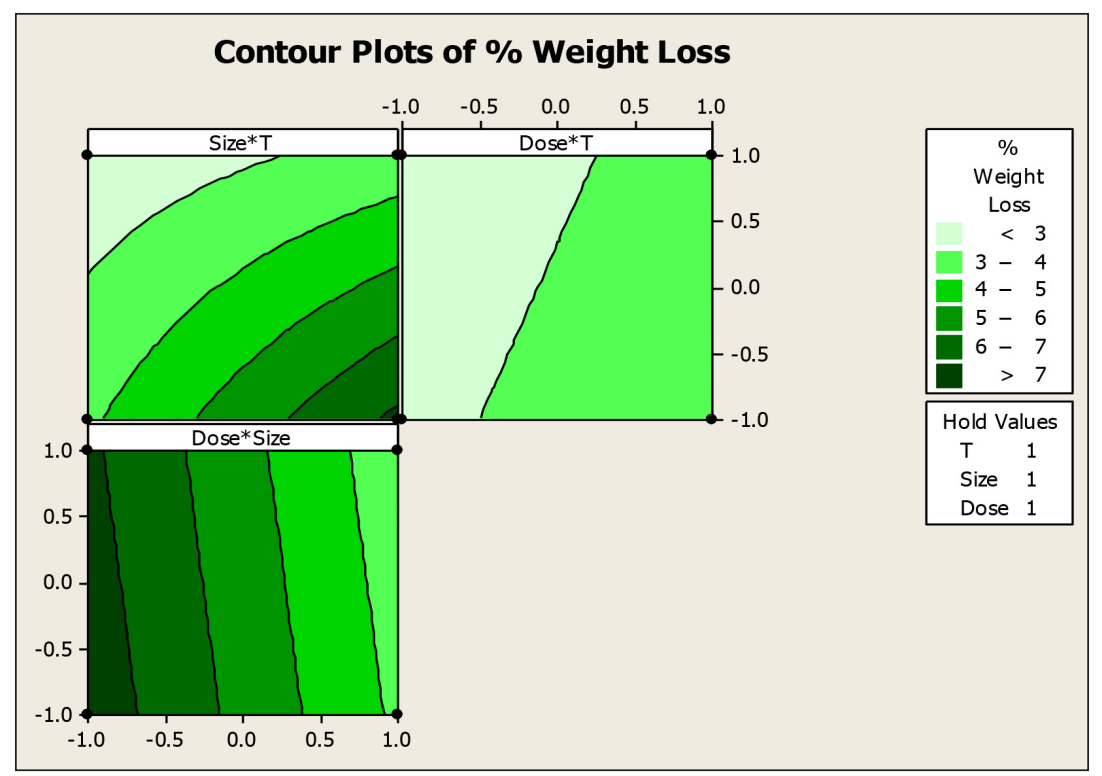

Figure 4: Contour plots of Size*T, Dose*T and Dose*Size

\section{Thermogravimetric Analysis}

Thermogravimetric analysis (TGA) used in this study is able to determine the decomposition of PP plastic. It was reported that the PP plastic exhibits low melting points at $164 \pm$ $1{ }^{\circ} \mathrm{C}$ (Majewsky et al., 2016). As can be seen from the TGA curve shown in Figure 5, the thermal decomposition process of PP starts at a temperature of $178^{\circ} \mathrm{C}$ and the maximum weight loss occurs in the range of 200 to $300^{\circ} \mathrm{C}$. No obvious weight loss was detected at 35 and $50^{\circ} \mathrm{C}$. This observation suggests that the weight loss measured during the treatment was solely due to the photodegradation reaction. Elevation of reaction temperature up to $50{ }^{\circ} \mathrm{C}$ possibly alters the activity on $\mathrm{ZnO}$ catalyst surface which encourages generation of radical species or promotes the oxidation reaction rate on plastic surface. In addition, exposure to that temperature weakened the chemical bonds in PP, thus increased the effectiveness of radical attacks.

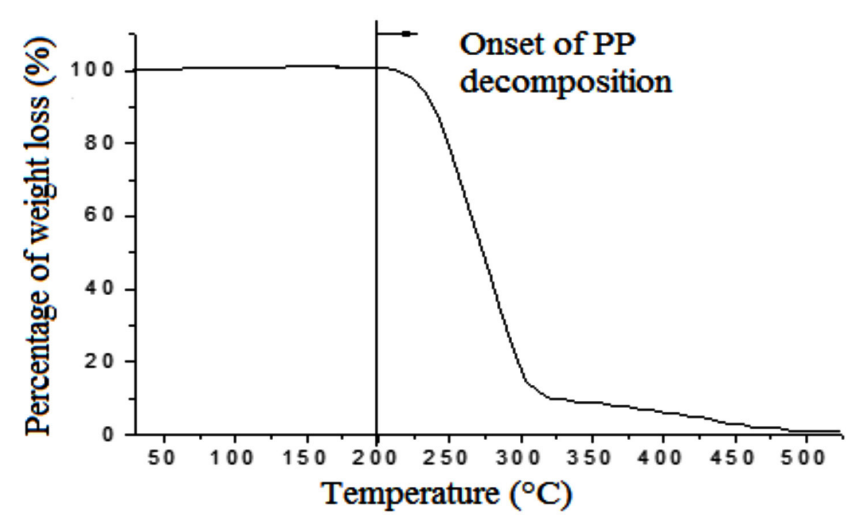

Figure 5: TGA analysis of PP plastic 


\section{SEM Analysis}

Figure 6 (a) shows the SEM micrograph of untreated PP plastic. Microcracks, cavities and interconnected holes were detected forming on the surface of treated PP (as shown in Figure 6(b) and (c)). In agreement with Ali et al., (2016), the development of these surface defects indicates the occurrence of polymer degradation or oxidation. Small cracks and isolated holes ( $<3 \mu \mathrm{m}$ diameter) were observed on the PP surface treated at $35{ }^{\circ} \mathrm{C}$ in the presence of $3 \mathrm{~g} / \mathrm{L}$ $\mathrm{ZnO}$ catalyst. The size of the microcracks grew to approximately more than $15 \mu \mathrm{m}$ diameter as the plastic was treated at $50{ }^{\circ} \mathrm{C}$ using $1 \mathrm{~g} / \mathrm{L}$ catalyst. The overall surface of the plastic was also becoming rough and irregular. The $\mathrm{ZnO}$ suspension initiates the photocatalysis process under UV light and it leads to aggressive oxidation of polymer chains that later creates holes or cracks.

\section{The Influence of Cyclic Thermo-photocatalytic Treatment on Polypropylene}

The impact of cyclic thermo-photocatalytic treatment on PP plastic degradation was tested over $25 \mathrm{~mm}^{2}$ plastic in presence of $1 \mathrm{~g} / \mathrm{L}$ of $\mathrm{ZnO}$ and $50^{\circ} \mathrm{C}$. The experimental works has been repeated for five cycles and the percentage of PP plastic weight loss has been summarised in Figure 7. As expected, high percentage of weight loss was observed on the increase of the number of treatments from $7.4 \%$ to $37.8 \%$. With more cycles, the plastic weight loss was higher. It is recommended that the number of treatment cycles can be prolonged to more than 5 cycles in future studies to further confirm the trend.

PP plastic is considered strong and has a good thermal resistance. The morphology of the plastic started to crack after the first treatment. The SEM micrograph of PP plastic after being treated for five times as indicated in Figure 8. The damage of the PP surface increases with
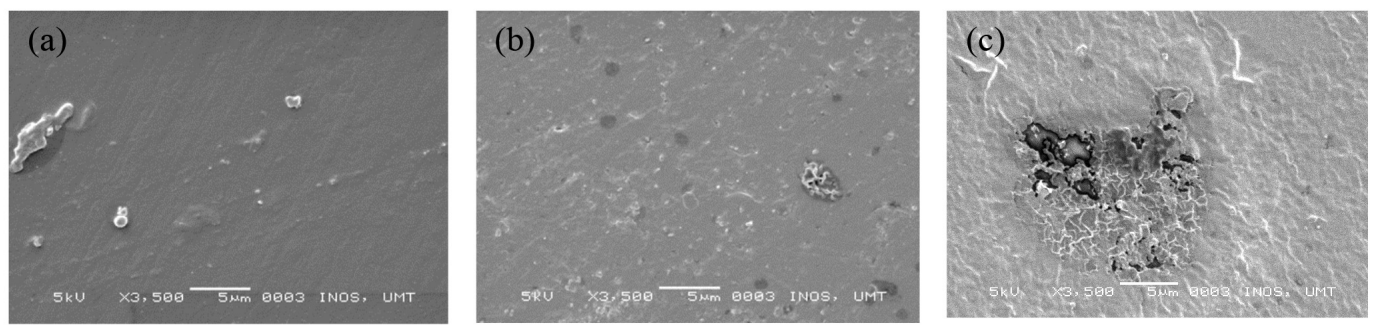

Figure 6: The SEM micrograph of (a) untreated PP plastic; (b) PP plastic treated using $3 \mathrm{~g} / \mathrm{L} \mathrm{ZnO}$ at $35^{\circ} \mathrm{C}$ and (c) PP plastic treated using $1 \mathrm{~g} / \mathrm{L} \mathrm{ZnO}$ at $50^{\circ} \mathrm{C}$

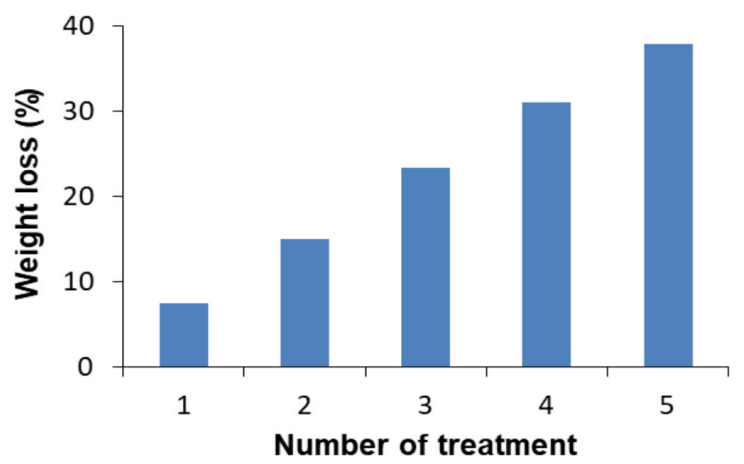

Figure 7: Percentage of plastic weight loss with number of thermo-photocatalytic treatment cycles 
increased exposure to light source and longer reaction time (Bandara et al., 2017).

Thermophotocatalytic process is expected to cause oxidative degradation of PP microplastics due to simultaneous thermal exposure and radical attacks by photogenerated reactive oxygen species on $\mathrm{ZnO}$ surface illuminated with UV. FTIR analysis has been performed to confirm the oxidative degradation of PP upon treatment. Figure 9 shows the comparison between the spectrum of untreated PP and the PP treated with thermophotocatlytic process for 5 cycles.
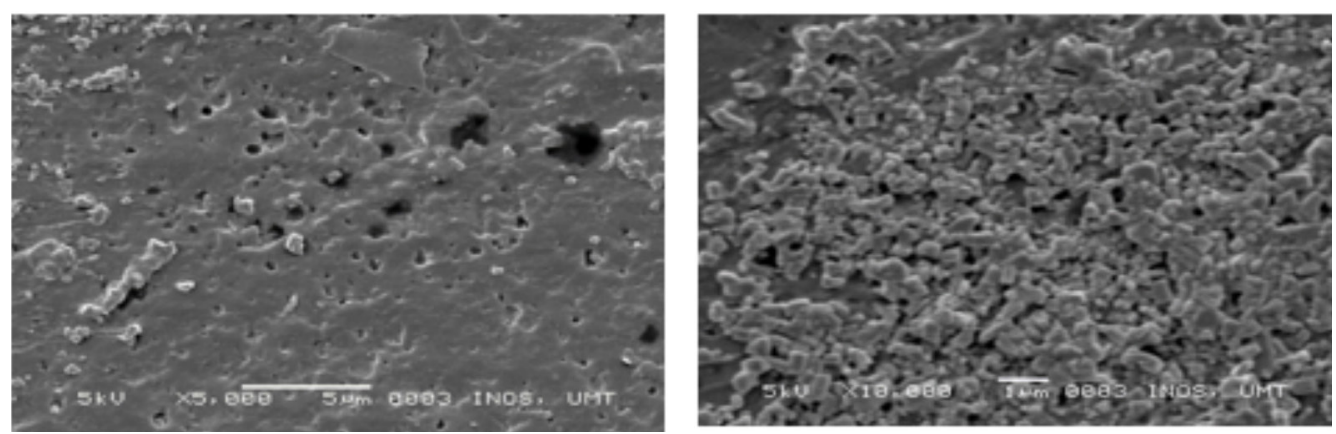

Figure 8: The SEM micrograph of PP plastic $\left(25 \mathrm{~mm}^{2}\right)$ treated using $1 \mathrm{~g} / \mathrm{L} \mathrm{ZnO}$ at $50^{\circ} \mathrm{C}$ after 5 cycles of thermo-photocatalytic treatment

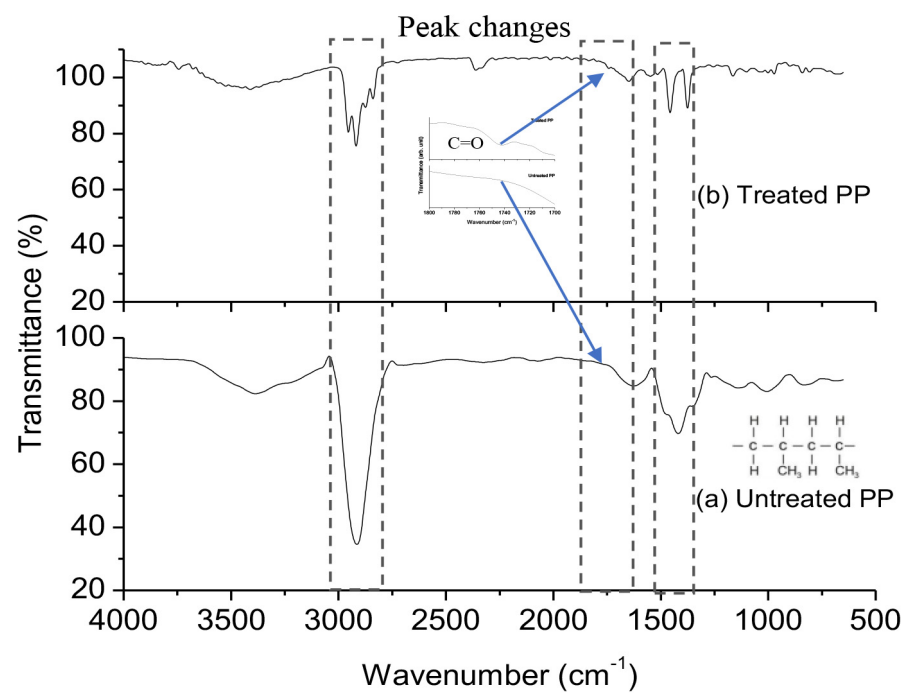

Figure 9: Wave number in diagram 
Table 4: The peaks detected from FTIR spectra of (a) untreated PP plastic and (b) $25 \mathrm{~mm}^{2} \mathrm{PP}$ plastic treated with $1 \mathrm{~g} / \mathrm{L} \mathrm{ZnO}$ at $50^{\circ} \mathrm{C}$ after being treated for 5 times.

\begin{tabular}{|c|c|c|c|}
\hline & Peak $\left(\mathrm{cm}^{-1}\right)$ & Assignment & References \\
\hline \multirow[t]{8}{*}{ Untreated PP } & 833 & Rocking vibration of $-\mathrm{CH}$ & \multirow{5}{*}{$\begin{array}{l}\text { Fang et al., 2012; Chun } \\
\text { et al., 2015; Jung et al., } \\
2018\end{array}$} \\
\hline & 1006 & Rocking vibration of $-\mathrm{CH}_{3}$ & \\
\hline & 1141 & Wagging/Rocking of $\mathrm{CH}$ or $\mathrm{CH}_{3}$ & \\
\hline & 1354 & $\begin{array}{l}\text { Symmetrical bending vibration of } \\
-\mathrm{CH}_{3}\end{array}$ & \\
\hline & 1419 & $\begin{array}{l}\text { Symmetrical bending vibration of } \\
-\mathrm{CH}_{3}\end{array}$ & \\
\hline & 1618 & $\mathrm{C}=\mathrm{C}$ stretching vibration & Longo et al., 2011 \\
\hline & 2914 & $\begin{array}{l}\text { Asymmetrical bending vibration of } \\
-\mathrm{CH}_{2}\end{array}$ & $\begin{array}{l}\text { Fang et al., 2012; Chun } \\
\text { et al., 2015; Jung et al., } \\
2018\end{array}$ \\
\hline & 3377 & Hydroxyl (-OH) group & Longo et al., 2011 \\
\hline \multirow{11}{*}{$\begin{array}{l}\text { Treated PP } \\
\text { (After } 5 \text { cycles of } \\
\text { treatment) }\end{array}$} & 840 & Rocking vibration of $-\mathrm{CH}$ & \multirow{5}{*}{$\begin{array}{l}\text { Fang et al., 2012; Chun } \\
\text { et al., 2015; Jung et al., } \\
2018\end{array}$} \\
\hline & 1022 & Rocking vibration of $-\mathrm{CH}_{3}$ & \\
\hline & 1161 & Wagging/Rocking of $\mathrm{CH}$ or $\mathrm{CH}_{3}$ & \\
\hline & 1375 & $\begin{array}{l}\text { Symmetrical bending vibration of } \\
-\mathrm{CH}_{3}\end{array}$ & \\
\hline & 1456 & $\begin{array}{l}\text { Symmetrical bending vibration of } \\
-\mathrm{CH}_{3}\end{array}$ & \\
\hline & 1647 & $\mathrm{C}=\mathrm{C}$ stretching vibration & Longo et al., 2011 \\
\hline & *1743 & \multirow{2}{*}{$\begin{array}{l}\text { (new peak merge) } \\
\text { Carbonyl }(\mathrm{C}=\mathrm{O}) \text { from ketone groups }\end{array}$} & \multirow{2}{*}{$\begin{array}{l}\text { Barbes et al., 2014; } \\
\text { Mylläri et al., 2015; } \\
\text { Longo et al., 2011; } \\
\text { Sellin \& Campos, } 2003\end{array}$} \\
\hline & *1832 & & \\
\hline & 2918 & $\begin{array}{l}\text { Asymmetrical bending vibration of } \\
-\mathrm{CH}_{2}\end{array}$ & $\begin{array}{l}\text { Fang et al., 2012; Chun } \\
\text { et al., 2015; Jung et al., } \\
2018\end{array}$ \\
\hline & *2926 & $\begin{array}{l}\text { (new peak merge) } \\
\mathrm{C}-\mathrm{H} \text { stretching from linear aliphatic } \\
\text { chain }\end{array}$ & \multirow[t]{2}{*}{ Longo et al., 2011} \\
\hline & 3410 & Hydroxyl (-OH) group & \\
\hline
\end{tabular}

An untreated PP molecule is made from polymerization of propene monomer $\left(\mathrm{C}_{3} \mathrm{H}_{6}\right)$ in which the non-polar methyl groups are attached to its long carbon chains. Based on previous works, oxidative degradation of PP is associated to the presence of oxidized polar functional groups such as carbonyl $(\mathrm{C}=\mathrm{O})$, hydroxyl $(-\mathrm{OH})$, (C-O) and (C-OH) (Barbes et al., 2014; Mylläri et al., 2015; Longo et al., 2011; Sellin \& Campos, 2003). Action by radiation, thermal exposure and/or oxidising agents particularly reactive oxygen species $\left(\cdot \mathrm{OH}, \cdot \mathrm{O}_{2}^{-}\right)$are responsible for the introduction of these new functional groups to the PP during degradation process. Based on FTIR result, important changes occurring in the region of 1600 to $3500 \mathrm{~cm}^{-1}$ was thoroughly analysed. It was noticed that several new peaks emerged at 1743, 1832 and $2926 \mathrm{~cm}^{-1}$ in treated PP. Consistent with Longo et al., (2011), Mylläri et al., (2015) and Sellin and Campos 
(2003), the appearance of these peaks could be associated with the presence of ketone groups. The presence of hydroxyl (-OH) groups around $3400 \mathrm{~cm}^{-1}$ in the spectrum of treated PP also indicates the surface of the PP has oxidised with more carboxyl groups (-COOH) and alcohol. Therefore, the FTIR analysis confirmed that upon treatment with thermal-photocatalytic process using $\mathrm{ZnO}$, oxidative degradation of $\mathrm{PP}$ occurred. Combination of heat, UV irradiation and chemical attack by reactive oxygen species induced by $\mathrm{ZnO}$ photocatalyst had effectively promote degradation of PP.

\section{Conclusion}

Degradation rate of PP macro and microplastics suspended in an aqueous environment has been significantly affected by the UV-assisted thermo-photocatalytic reaction over $\mathrm{ZnO}$ at elevation of reaction temperature. $\mathrm{ZnO}$ photocatalyst which was activated by UV light induced the photogeneration of reactive radical species (superoxides or hydroxyl radicals). These highly oxidising agents rapidly attacked and oxidised the polar functional groups on PP. The photodegradation rate of PP was further promoted by increasing the reaction temperature $\left(\sim 50^{\circ} \mathrm{C}\right)$. As a result, fragmentation of macroand microplastic was accelerated. The $2^{3}$ full factorial analysis statistically proved that the reaction temperature, size of $\mathrm{PP}$ plastic and interaction of both variables are important factors that need to be taken into consideration. However, the $\mathrm{ZnO}$ catalyst dosage has a little impact on the PP plastic degradation. The decomposition of microplastic $\left(25 \mathrm{~mm}^{2}\right)$ was the highest $(7.89 \%)$ upon the introduction of $1 \mathrm{~g} / \mathrm{L}$ of $\mathrm{ZnO}$ and the reaction was carried out at $50^{\circ} \mathrm{C}$. In addition, the degradability of microplastics increased linearly with increasing number of treatment; in which $38 \%$ of PP plastic was degraded after being treated for five cycles. With similar number of treatment cycles, the percentage of PP weight loss can be maximised if the treatment was conducted on microplastics with much smaller size $\left(<25 \mathrm{~mm}^{2}\right)$. This would be an advantage to treat microplastic debris in actual wastewater which commonly ranging from $25 \mathrm{~mm}^{2}$ to $1 \mathrm{~nm}^{2}$. All these work contributed to the knowledge in improving the microplastic degradation from the influence catalyst loading, influence of reaction temperature and influence of microplastic size.

\section{Acknowledgements}

NR gratefully acknowledges the Universtity Malaysia Terengganu for award of TAPE-RG Vot., 55179.

\section{References}

Abo, R., Kummer, N., \& Merkel, B. J. (2016). Optimized photodegradation of Bisphenol $\mathrm{A}$ in water using $\mathrm{ZnO}, \mathrm{TiO}_{2}$ and $\mathrm{SnO}_{2}$ photocatalysts under UV radiation as a decontamination procedure. Drinking Water Engineering and Science, 9, 27-35.

Ali, S. S., Qazi, I. A., Arshad, M., Khan, Z., Voice, T. C., \& Mehmood, C. T. (2016). Photocatalytic degradation of low density polyethylene ( LDPE ) films using titania nanotubes. Environmental Nanotechnology, Monitoring and Management, 5, 44-53.

Andrady, A. L. (2011). Microplastics in the marine environment. Marine Pollution Bulletin, 62, 1596-1605.

Ariza-Tarazona, M. C., Villarreal-Chiu, J. F., Barbieri, V., Siligardi, C., \& CedilloGonzález, E. I. (2019). New strategy for microplastic degradation: Green photocatalysis using a protein-based porous $\mathrm{N}-\mathrm{TiO}_{2}$ semiconductor. Ceramics International, 45(7), 9618-9624.

Bandara, W. R. N., Silva, R. M. de, Silva, K. M. N. de, Dahanayake, D., Gunasekara, S., \& Thanabalasingam, K. (2017). Is nano $\mathrm{ZrO}_{2}$ a better photocatalyst than nano $\mathrm{TiO}_{2}$ for degradation of plastics? RSC Advances, 7, 46155-46163.

Barbes, L., Radulescu, C., \& Stihi, C. (2014). ATR-FTIR spectrometry characterisation of polymeric materials. Romanian Report in Physics, 66, 765-777. 
Benckiser, G. (2019). Plastics, Micro- and Nanomaterials, and Virus-Soil MicrobePlant Interactions in the Environment. In Plant Nanobionics. Cham: Springer.

Chun, K. S., Husseinsyah, S., \& Osman, H. (2015). Utilization of cocoa pod husk as filler in polypropylene biocomposites: Effect of maleated polypropylene. Journal of Thermoplastic Composite Materials, 28, 1507-1521.

Clean Malaysia. (2016). Drowning the oceans in plastic waste. Retrieved January 20, 2019, from Clean Malaysia website: https:// cleanmalaysia.com/2016/04/19/drowningthe-oceans-in-plastic-waste/

Fang, J., Zhang, L., Sutton, D., Wang, X., \& Lin, T. (2012). Needleless melt-electrospinning of polypropylene nanofibres. Journal of Nanomaterials, 2012, 16.

Jung, M. R., Horgen, F. D., Orski, S. V., Rodriguez, V., Beers, K. L., Balazs, G. H., Jones, T. T., Work, T. M., Brignac, K. C., Royer, S. J., \& Hyrenbach, K. D. (2018). Validation of ATR FT-IR to identify polymers of plastic marine debris, including those ingested by marine organisms. Marine Pollution Bulletin, 127, 704-716.

Kang, J., Zhou, L., Duan, X., Sun, H., Ao, Z., \& Wang, S. (2019). Degradation of cosmetic microplastics via functionalized carbon nanosprings. Matter, 1, 745-758.

Kay, P., Hiscoe, R., Moberley, I., Bajic, L., \& McKenna, N. (2018). Wastewater treatment plants as a source of microplastics in river catchments. Environmental Science and Pollution Research, 25, 20264-20267.

Lambert, S., \& Wagner, M. (2016). Characterisation of nanoplastics during the degradation of polystyrene. Chemosphere, $145,265-268$.

Laxma, P. V., Kim, K., Kavitha, B., Kumar, V., Raza, N., \& Kalagara, S. (2018). Photocatalytic degradation of bisphenol A in aqueous media: A review. Journal of Environmental Management, 213, 189-205.
Longo, C., Savaris, M., Zeni, M., Brandalise, R. N., \& Grisa, A. M. C. (2011). Degradation study of polypropylene (PP) and bioriented polypropylene (BOPP) in the environment. Materials Research, 14(4), 442-448.

Majewsky, M., Bitter, H., Eiche, E., \& Horn, H. (2016). Determination of microplastic polyethylene (PE) and polypropylene (PP) in environmental samples using thermal analysis (TGA-DSC). Science of the Total Environment, 568, 507-511.

Mylläri, V., Ruoko, T. P., \& Syrjälä, S. (2015). A comparison of rheology and FTIR in the study of polypropylene and polystyrene photodegradation. Journal of Applied Polymer Science, 132(28), 42246.

Piehl, S., Liener, A., Loder, M. G. J., Dris, R., Bogner, C., \& Laforsch, C. (2018). Identification and quantification of macroand microplastics on an agricultural farmland. Scientific Reports, 8, 1-9.

Portillo, F., Yashchuk, O., \& Hermida, É. (2016). Evaluation of the rate of abiotic and biotic degradation of oxo-degradable polyethylene. Polymer Testing, 53, 58-69.

Prata, J. C. (2018). Microplastics in wastewater: State of the knowledge on sources, fate and solutions. Marine Pollution Bulletin, 129, 262-265.

Sellin, N., \& Campos, J. S. D. C. (2003). Surface composition analysis of PP films treated by corona discharge. Materials Research, 6(2), 163-166.

Shim, W. J., Hong, S. H., \& Eo, S. E. (2017). Identification methods in microplastic analysis: A review. Analytical Methods, 9(9), 1384-1391.

Tofa, T. S., Laxman, K., Swaraj, K., \& Joydeep, P. (2019a). Visible light photocatalytic degradation of microplastic residues with zinc oxide nanorods. Environmental Chemistry Letters. 1-6.

Tofa, T. S., Ye, F., Kunjali, K. L., \& Dutta, J. (2019b). Enhanced visible light 
photodegradation of microplastic fragments with plasmonic platinum/zinc oxide nanorod photocatalysts. Catalysts, 9, 819.

Valavanidis, A. (2016). Global Plastic Waste and Oceans Pollution Million tons of Plastic Waste Have Gone Missing in the World Oceans. Athens, Greece, May.

Weinstein, J., Crocker, B., \& Gray, A. (2016). From macroplastic to microplastic: Degradation of high-density polyethylene, polypropylene, and polystyrene in a salt marsh habitat. Environmental Toxicology and Chemistry, 35, 1632-1640.

Zhao, X., Li, Z., Chen, Y., Shi, L., \& Zhu, Y. (2008). Enhancement of photocatalytic degradation of polyethylene plastic with $\mathrm{CuPc}$ modified $\mathrm{TiO}_{2}$ photocatalyst under solar light irradiation. Applied Surface Science, 254, 1825-1829. 